\title{
Releasing Migrants from Detention During the Covid-19 Pandemic
}

\author{
Katherine C. McKenzie, MD, FACP ${ }^{\top}$ and Ranit Mishori, MD, MHS, FAAFP ${ }^{2,3}$ \\ 'Department of Internal Medicine, Yale School of Medicine, New Haven, CT, USA; ${ }^{2}$ Physicians for Human Rights, New York, NY, USA; ${ }^{3}$ Department of \\ Family Medicine, Georgetown University School of Medicine, Washington, DC, USA.
}

$\mathrm{J}$ Gen Intern Med 35(9):2765-6

DOI: $10.1007 / \mathrm{s} 11606-020-05954-4$

(c) Society of General Internal Medicine 2020

${ }^{66} 1$ am terrified of getting the coronavirus." "No one can social distance." "The guards have masks, but we don't." This is what migrants in detention are telling their attorneys in the middle of the Covid-19 pandemic. They're in grave danger, and they are reaching out for help. They live in overcrowded, unsanitary facilities and the desperation they feel has only increased along with the numbers of those testing positive.

Many asylum seekers who enter the country are placed in carceral settings while awaiting their immigration hearings. They are not criminals, but because of our government's harsh policies, they are held in prison-like facilities. In the past, asylum seekers often awaited adjudication while living in the community, and the vast majority - greater than $90 \%$ by some counts ${ }^{1}$ — complied with legal requirements as their cases were evaluated. In the last three years, the Trump administration has prioritized detention of asylum seekers and the number of individuals in immigration detention has increased significantly_right now, approximately 30,000 people are currently being held in immigration detention facilities in the USA. ${ }^{2}$

The confluence of tens of thousands of individuals in detention with a global pandemic is a perfect storm - a situation that could affect the health of detainees and staff, strain local community health systems, and ultimately result in many preventable deaths. Infectious disease outbreaks in detention centers have been poorly managed in the past, causing significant morbidity and mortality, at higher rates than in the community. ${ }^{3}$ SARS-CoV-2 remains an elusive and poorly understood virus that is ten times more infectious than influenza, has no vaccine, and no preventative therapy. We also do not know if infection with the novel coronavirus confers immunity.

The risk of contracting coronavirus is significantly increased in congregate settings - cruise ships, naval carriers, nursing homes, and long-term care facilities - and this risk is compounded in resource-stressed facilities such as prisons,

Received May 20, 2020

Accepted May 29, 2020

Published online June 15, 2020 jails, and detention facilities. These are all places where social distancing - the cornerstone of methods to protect individuals from contracting the infection-is simply not possible.

Immigration detention essentially traps hundreds of people in close quarters and in unsanitary conditions, while staff members come and go multiple times a day, each time potentially introducing the virus into the building. As doctors who have spent time in detention centers before the outbreak, we have seen just how little personal space detainees have. Now they tell us of inadvertently brushing the arm of the person at a crowded lunch table. They describe, with anguish, hearing as their roommate begins to cough. They may be allotted only one small bar of soap a week, and realize with dread that it will not begin to last that long.

Even the most rudimentary personal protective equipment (PPE), such as non-N95 surgical masks and gloves, is in short supply, to say nothing of the more effective barriers that are required when interacting with symptomatic or infected patients. When the busiest hospitals in the country do not have enough PPE, there is surely little left over for immigration detention centers.

The ability to prevent the spread of the novel coronavirus by the methods recommended by the Centers for Disease Control and Prevention leaves these vulnerable individuals at high risk for infection. Screening and testing protocols, limited in the USA, are even more so in detention centers. Medical care of those who become ill is not available in these centers, where negative pressure rooms are scarce, medical staffing is stretched thin, and the need for isolation rooms often mean resorting to solitary confinement. A Covid-19 outbreak can quickly overwhelm not only the facilities themselves, but also health resources in surrounding communities, especially in rural areas.

Detainees are not the only ones at risk for coronavirus infection and Covid-19. Detention staff and their families and associates have become ill when the people they are overseeing are infected. Although they may have more protection available to them than the detainees, prevention remains impaired.

In response to the dire circumstances migrants in detention are experiencing, a collaboration has been fostered between physicians and public health experts, lawyers, and human rights organizations, all calling for the release of detainees from immigration detention. Many in the medical community have partnered with legal and human rights colleagues in the \#FreeThemAll campaign. ${ }^{4}$ 
These efforts include joint letters, press briefings, and advocacy campaigns, as well as a slew of emergency litigation led by legal aid groups such as ACLU, LegalAid Society, and the National Immigration Law Center, among others. ${ }^{5}$ By writing a medical-legal declaration appealing for the release of detainees, physicians can use their expertise and authority to educate judges about the medical risks of detention, and appeal especially on behalf of inmates who are at high risk for developing severe Covid-19. Multiple cases around the country are ongoing and awaiting judges' decisions, while others have resulted in detainee release. In cases where physicians contribute, attorneys have noted the importance of a medical opinion when arguing the cases.

The immigration detention system is not safe for detainees, staff, or the surrounding communities during a pandemic. There is no justification for keeping these individuals, who have not been convicted of any crime, in this high-risk setting. They must be released into the community to self-quarantine and socially isolate, as most of the rest of the USA is able to do. The least effective and most expensive way of managing the Covid-19 outbreak is to keep individuals in detention; home quarantine and community management is the best option. It is our duty as physicians to speak out about the imminent danger to those in immigration detention and demand that ICE, local authorities, and elected officials act. As we work to control the pandemic and decrease morbidity and mortality from Covid-19, it has never been clearer that there are no benefits, to individuals or society, to keeping migrants locked up amid these grave risks.

Corresponding Author: Katherine C. McKenzie, MD, FACP; Department of Internal Medicine, Yale School of Medicine, New Haven, CT, USA (e-mail: katherine.mckenzie@yale.edu).

\section{Compliance with Ethical Standards:}

Conflict of Interest: The authors acknowledge that they do not have a conflict of interest.

\section{REFERENCES}

1. A Better Way: Community-Based Programming as An Alternative to Immigrant Incarceration. National Immigrant Justice Center. 2019. https://immigrantjustice.org/research-items/report-better-way-community-based-programming-alternative-immigrant-incarceration. Accessed April 28, 2020.

2. Detention Management. US Immigration and Customs Enforcement. https://www.ice.gov/detention-management. Accessed April 28, 2020.

3. Potter Christina. Outbreaks in Migrant Detention Facilities. Outbreak Observatory. July 1, 2011. https://www.outbreakobservatory.org/ outbreakthursday-1/7/11/2019/outbreaks-in-migrant-detention-facilities. Accessed April 28, 2020.

4. COVID-19: Free Them All. Detention Watch Network. 2020. https://www. detentionwatchnetwork.org/covid-19. Accessed April 28, 2020.

5. ACLU Sues for Drastic Reduction in Population of Overcrowded Otay Mesa, Imperial Detention Centers. American Civil Liberties Union. April 21, 2020. https://www.aclusandiego.org/aclu-sues-for-drastic-reductionin-population-of-overcrowded-otay-mesa-imperial-detention-centers/. Accessed April 28, 2020.

Publisher's Note: Springer Nature remains neutral with regard to jurisdictional claims in published maps and institutional affiliations. 